\title{
Metformin suppresses hepatic gluconeogenesis and lowers fasting blood glucose levels through reactive nitrogen species in mice
}

\author{
Y. Fujita • M. Hosokawa • S. Fujimoto • E. Mukai • \\ A. Abudukadier • A. Obara • M. Ogura • Y. Nakamura • \\ K. Toyoda $\cdot$ K. Nagashima $\cdot$ Y. Seino $\cdot$ N. Inagaki
}

Received: 25 January 2010 / Accepted: 24 February 2010 /Published online: 29 March 2010

(C) Springer-Verlag 2010

\begin{abstract}
Aims/hypothesis Metformin, the major target of which is liver, is commonly used to treat type 2 diabetes. Although metformin activates AMP-activated protein kinase (AMPK) in hepatocytes, the mechanism of activation is still not well known. To investigate AMPK activation by metformin in liver, we examined the role of reactive nitrogen species (RNS) in suppression of hepatic gluconeogenesis.

Methods To determine RNS, we performed fluorescence examination and immunocytochemical staining in mouse hepatocytes. Since metformin is a mild mitochondrial complex I inhibitor, we compared its effects on suppression of gluconeogenesis, AMPK activation and generation of the RNS peroxynitrite $\left(\mathrm{ONOO}^{-}\right)$with those of rotenone, a representative complex I inhibitor. To determine whether
\end{abstract}

Y. Fujita $\cdot$ M. Hosokawa $(\bowtie) \cdot$ S. Fujimoto $\cdot$ E. Mukai $\cdot$

A. Abudukadier $\cdot$ A. Obara $\cdot$ M. Ogura $\cdot$ Y. Nakamura $\cdot$

K. Toyoda $\cdot$ K. Nagashima $\cdot$ Y. Seino $\cdot$ N. Inagaki

Department of Diabetes and Clinical Nutrition,

Graduate School of Medicine, Kyoto University,

54 Shogoin, Kawahara-cho, Sakyo-ku,

Kyoto 606-8507, Japan

e-mail: hosokawa@metab.kuhp.kyoto-u.ac.jp

E. Mukai

Japan Association for the Advancement of Medical Equipment,

Tokyo, Japan

Y. Seino

Kansai Electric Power Hospital,

Osaka, Japan

S. Fujimoto $\cdot$ K. Nagashima $\cdot$ N. Inagaki

CREST of Japan Science and Technology Cooperation (JST),

Kyoto, Japan endogenous nitric oxide production is required for $\mathrm{ONOO}^{-}$ generation and metformin action, we used mice lacking endothelial nitric oxide synthase (eNOS).

Results Metformin and rotenone significantly decreased gluconeogenesis and increased phosphorylation of AMPK in wild-type mouse hepatocytes. However, unlike rotenone, metformin did not increase the AMP/ATP ratio. It did, however, increase $\mathrm{ONOO}^{-}$generation, whereas rotenone did not. Exposure of eNOS-deficient hepatocytes to metformin did not suppress gluconeogenesis, activate AMPK or increase $\mathrm{ONOO}^{-}$generation. Furthermore, metformin lowered fasting blood glucose levels in wildtype diabetic mice, but not in eNOS-deficient diabetic mice.

Conclusions/interpretation Activation of AMPK by metformin is dependent on $\mathrm{ONOO}^{-}$. For metformin action in liver, intra-hepatocellular eNOS is required.

Keywords AMP. AMP-activated protein kinase . Endothelial nitric oxide synthase - Gluconeogenesis . Metformin · Nitric oxide · Peroxynitrite ·

Reactive nitrogen species

$\begin{array}{ll}\text { Abbreviations } \\ \text { AMPK } & \text { AMP-activated protein kinase } \\ \text { BAEC } & \text { Bovine aortic endothelial cells } \\ \text { DCDHF } & \text { 2,7-Dihydrodichlorofluorescein } \\ \text { eNOS } & \text { Endothelial nitric oxide synthase } \\ \text { L-NAME } & N^{\omega} \text {-Nitro-L-arginine methyl ester } \\ \text { NOS } & \text { Nitric oxide synthase } \\ \text { OCT1 }^{-} & \text {Organic cation transporter 1 } \\ \text { ONOO }^{-} & \text {Peroxynitrite } \\ \text { RNS } & \text { Reactive nitrogen species }\end{array}$




\section{Introduction}

Metformin is one of the most commonly used oral glucoselowering drugs for type 2 diabetes and is recommended as a first-line drug in recent treatment guidelines of the American Diabetes Association and European Association for the Study of Diabetes [1, 2]. The main target tissue of metformin is liver and its major effect is to decrease hepatic glucose output, which occurs largely due to the suppression of gluconeogenesis, leading to lower fasting blood glucose levels without insulin stimulation and weight gain [3-5]. In addition, metformin has beneficial effects on cardiovascular function and reduces cardiovascular risk in type 2 diabetes [6].

Although metformin has been used clinically for several decades, the mechanisms by which it exerts its glucoselowering effects are still unclear [7]. Recent studies have demonstrated that therapeutic effects of metformin are mediated by activation of AMP-activated protein kinase (AMPK), leading to a decrease in gluconeogenesis and an increase of fatty acid oxidation in liver and of glucose uptake in skeletal muscle [8-10]. AMPK is a serine/ threonine kinase that acts as an energy sensor and is activated in response to reductions of cellular energy levels and to environmental stress, including hypoxia, ischaemia, exercise, ATP depletion and oxidative stress [11, 12]. Although it has been known that AMPK is activated by an increase in the AMP/ATP ratio, the AMPK-activating mechanism also involves other pathways that are dependent on upstream AMPK kinases, including LKB1 kinase and calmodulin-dependent protein kinase kinase in liver and skeletal muscle, respectively [13]. Previous studies reported that metformin had an inhibitory effect on mitochondrial complex I; and, indeed, an inhibition of mitochondrial complex I has been found to increase the AMP/ATP ratio $[7,14,15]$. AMPK activation by metformin was therefore thought to be also mediated by an increase in the AMP/ATP ratio. However, recent studies have reported that metformin action may be mediated without a notable inhibition of mitochondrial metabolism $[10,16]$.

Recently, a possible role of peroxynitrite $\left(\mathrm{ONOO}^{-}\right)$, a reactive nitrogen species (RNS), in the mechanism of AMPK activation has been investigated. RNS comprises nitric oxide and its secondary substrates; $\mathrm{ONOO}^{-}$is generated from superoxide anions $\left(\mathrm{O}_{2}{ }^{-}\right)$and nitric oxide [17]. Zou et al. reported that metformin activates AMPK through $\mathrm{ONOO}^{-}$in bovine aortic endothelial cells (BAEC) [18]. However, it is unclear whether RNS generation by metformin is involved in its suppression of hepatic gluconeogenesis or whether RNS generation affects metformin's pharmacological action in lowering of fasting blood glucose levels.

To clarify the mechanism of AMPK activation in liver, we used mouse hepatocytes to investigate the involvement of the AMP/ATP ratio and RNS in AMPK activation by metformin compared with rotenone, a representative complex I inhibitor. To determine whether endogenous nitric oxide production is required for metformin action in hepatocytes, we also performed experiments using mice lacking endothelial nitric oxide synthase (eNOS) [18-21]. We demonstrated that $\mathrm{ONOO}^{-}$plays a critical role in AMPK activation by metformin in liver and that eNOS is required for metformin action in vitro and in vivo.

\section{Methods}

Animals Male C57/BL6 (wild-type) mice were obtained from Shimizu (Kyoto, Japan). Male eNOS-deficient (eNos [also known as Nos3 $]^{-1-}$ ) mice were obtained from Jackson Laboratories (Bar Harbor, ME, USA). Mice were maintained in a temperature-controlled $\left(25 \pm 2^{\circ} \mathrm{C}\right)$ environment with a $12 \mathrm{~h} \mathrm{light/dark} \mathrm{cycle.} \mathrm{The} \mathrm{mice} \mathrm{had} \mathrm{free} \mathrm{access} \mathrm{to}$ standard laboratory chow and water. All experiments were carried out with mice aged 8 to 10 weeks. The animals were maintained and used in accordance with the Guidelines for Animal Experiments of Kyoto University. All the experiments involving animals were conducted in accordance with the Guidelines for Animal Experiments of Kyoto University and were approved by the Animal Research Committee, Graduate School of Medicine, Kyoto University.

Hepatocyte preparation and culture Mice hepatocytes were isolated by collagenase digestion as described previously [22]. Primary hepatocytes were prepared by seeding in six well type 1 collagen-coated plates at a density of $1.5 \times$ $10^{6}$ cells in DMEM (low glucose, $5.6 \mathrm{mmol} / \mathrm{l}$ ) containing $10 \%$ (vol./vol.) FBS, $100 \mathrm{nmol} / 1$ regular insulin, $50 \mathrm{U} / \mathrm{ml}$ penicillin and $50 \mu \mathrm{g} / \mathrm{ml}$ streptomycin. Hepatocytes were then cultured overnight in a humidified atmosphere $\left(5 \% \mathrm{CO}_{2}\right)$ at $37^{\circ} \mathrm{C}$.

Glucose production via gluconeogenesis in hepatocytes Gluconeogenesis was measured as described previously with slight modifications $[22,23]$. In brief, freshly isolated hepatocytes from mice fasted for $16 \mathrm{~h}$ were treated in 24 well plates $\left(7.5 \times 10^{5}\right.$ cells/well $)$ in $0.5 \mathrm{ml} \mathrm{KRB}$ buffer (119.4 mmol/ $1 \mathrm{NaCl}, 3.7 \mathrm{mmol} / \mathrm{l} \mathrm{KCl}, 2.7 \mathrm{mmol} / \mathrm{l} \mathrm{CaCl}$, $1.3 \mathrm{mmol} / 1 \mathrm{KH}_{2} \mathrm{PO}_{4}, 1.3 \mathrm{mmol} / 1 \mathrm{MgSO}_{4}, 24.8 \mathrm{mmol} / \mathrm{l}$ $\mathrm{NaHCO}_{3}$ ) containing $2 \%$ (wt/vol.) BSA, $2 \mathrm{mmol} / \mathrm{l}$ oleate, $0.24 \mathrm{mmol} / 1$ 3-isobutyl-1-methylxanthine and gluconeogenetic substrates $(1 \mathrm{mmol} / \mathrm{l}$ pyruvate plus $10 \mathrm{mmol} / \mathrm{l}$ lactate) treated with metformin (Sigma, St Louis, MO, USA) and rotenone (Nacalai Tesque, Kyoto, Japan). Metformin was dissolved in water. Rotenone was dissolved in dimethyl sulfoxide to a concentration that did not interfere with cell viability (maximally $0.1 \%$ vol./vol.). 
The glucose content of the supernatant fraction was measured by the glucose oxidation method using an assay kit (Gopod; Megazyme, Wicklow, Ireland). The data were normalised by protein content measured by cell lysates.

Immunoblotting analysis Freshly isolated hepatocytes were treated with metformin, rotenone and $\mathrm{ONOO}^{-}$ (Dojindo, Kumamoto, Japan) in KRB buffer containing $2 \%$ (wt/vol.) BSA, $2 \mathrm{mmol} / 1$ oleate, $0.24 \mathrm{mmol} / \mathrm{l} 3$ isobutyl-1-methylxanthine and gluconeogenetic substrates ( $1 \mathrm{mmol} / \mathrm{l}$ pyruvate plus $10 \mathrm{mmol} / 1$ lactate). Primary hepatocytes cultured overnight were incubated in FBS-free DMEM (no glucose) treated with metformin and rotenone. The hepatocytes were homogenised in lysis buffer (50 mmol/1 Tris- $\mathrm{HCl}, \mathrm{pH}$ 7.4, $50 \mathrm{mmol} / \mathrm{l} \mathrm{NaF}, 1 \mathrm{mmol} / 1$ sodium pyrophosphate, $1 \mathrm{mmol} / \mathrm{l}$ EDTA, $1 \mathrm{mmol} / 1 \mathrm{EGTA}$, $1 \mathrm{mmol} / 1$ dithiothreitol, $0.1 \mathrm{mmol} / \mathrm{l}$ benzamidine, $0.1 \mathrm{mmol} / 1$ phenylmethylsulfonylfluoride, $0.2 \mathrm{mmol} / 1$ sodium vanadate, $250 \mathrm{mmol} / 1$ mannitol, 1\% (vol./vol.) Triton X-100 and $5 \mu \mathrm{g} / \mathrm{ml}$ soybean trypsin inhibitor). Cell lysates (50 to $150 \mu \mathrm{g}$ protein per lane) were subjected to electrophoresis on $8 \%$ (vol./vol.) SDS-polyacrylamide gels and transferred on to nitrocellulose membranes (Protran; Schleicher and Schuell, Keene, NH, USA). Blotted membranes were incubated with each primary antibody (1:1,000 dilution). Antibodies against AMPK $\alpha$ and phospho-AMPK $\alpha\left(\mathrm{Thr}^{172}\right)$ were from Cell Signaling Technology (Danvers, MA, USA). Antibodies against organic cation transporter 1 (OCT1) and glyceraldehyde-3-phosphate dehydrogenase were from Santa Cruz Biotechnology (Santa Cruz, CA, USA). Membranes were incubated with horseradish peroxidase-linked second antibodies (1:2,000 dilution) (GE Healthcare, Tokyo, Japan) and fluorescent bands were visualised using a western blotting detection system (Amersham ECL Plus; GE Healthcare) and then quantified by densitometry using Image $\mathrm{J}$ software from National Institutes of Health (Bethesda, MD, USA).

Determination of reactive nitrogen species $\mathrm{ONOO}^{-}$generation was measured using 2,7-dihydrodichlorofluorescein (DCDHF) diacetate (Cayman Chemical, Ann Arbor, MI, USA) [24-26], which is readily oxidised by $\mathrm{ONOO}^{-}$to the highly fluorescent product, dichlorofluorescein. Alone, nitric oxide, superoxide anions or hydrogen peroxide did not oxidise DCDHF. Freshly isolated hepatocytes were washed in ice-cold PBS and preloaded for $20 \mathrm{~min}$ at $37^{\circ} \mathrm{C}$ with $10 \mu \mathrm{mol} / 1 \mathrm{DCDHF}$ diacetate (Cayman Chemical) in KRB buffer containing 2\% (wt/vol.) BSA, $2 \mathrm{mmol} / \mathrm{l}$ oleate, $0.24 \mathrm{mmol} / 1 \mathrm{l}$ 3-isobutyl-1-methylxanthine and gluconeogenetic substrates $(1 \mathrm{mmol} / \mathrm{l}$ pyruvate plus $10 \mathrm{mmol} / \mathrm{l}$ lactate). Fluorescence was determined using a spectrofluorophotometer (RF-5300PC; Shimazu, Kyoto, Japan) with excitation wavelength at $502 \mathrm{~nm}$ and emission wavelength at $523 \mathrm{~nm}$. After $1 \mathrm{~h}$ incubation in the presence or absence of metformin, rotenone, $\mathrm{ONOO}^{-}$or hydrogen peroxide with or without RNS scavenger $(5 \mathrm{mmol} / \mathrm{l} \alpha$ tocopherol plus $2.3 \mathrm{mmol} / \mathrm{l}$ ascorbate) [27], fluorescence was measured and presented as a ratio with respect to the value at time zero.

Immunocytochemistry Primary hepatocytes were plated on cover glass coated with $0.01 \%$ (vol./vol.) poly-L-lysine (Sigma) in six-well plates $\left(5.0 \times 10^{5}\right.$ cells per well). Hepatocytes were then incubated with FBS-free DMEM (no glucose) in the presence or absence of rotenone, metformin, metformin with RNS scavenger $(5 \mathrm{mmol} / \mathrm{l} \alpha$ tocopherol plus $2.3 \mathrm{mmol} / \mathrm{l}$ ascorbate) and metformin with $1 \mathrm{mmol} / 1$ of the nitric oxide synthase (NOS) inhibitor $N^{\omega}$ nitro-L-arginine methyl ester (L-NAME) for $2 \mathrm{~h}$, or in the presence or absence of $\mathrm{ONOO}^{-}$for $5 \mathrm{~min}$. The hepatocytes were fixed in $3.7 \%$ (wt/vol.) paraformaldehyde and incubated with rabbit polyclonal anti-nitrotyrosine antibody (1:100 dilution; Millipore; Billerica, MA, USA). Next, cells were incubated with goat anti-rabbit IgG fluoresceinconjugated secondary antibody (1:100 dilution; Alexa Fluor 488; Invitrogen, Carlsbad, CA, USA). Fluorescence in cells was monitored using a laser scanning microscope (LSM 510; Carl Zeiss, Tokyo, Japan) for confocal microscopy and a software package (LSM 510 Meta; Carl Zeiss) for image acquisition.

Measurement of adenine nucleotide content After freshly isolated hepatocytes were incubated in KRB buffer containing 2\% (wt/vol.) BSA, $2 \mathrm{mmol} / 1$ oleate, $0.24 \mathrm{mmol} / 13$ isobutyl-1-methylxanthine and gluconeogenetic substrates ( $1 \mathrm{mmol} / \mathrm{l}$ pyruvate plus $10 \mathrm{mmol} / \mathrm{l}$ lactate) in the presence or absence of metformin or rotenone for $2 \mathrm{~h}$, or of $\mathrm{ONOO}^{-}$ for $5 \mathrm{~min}$, treatment was stopped by rapid addition of $0.1 \mathrm{ml}$ of $2 \mathrm{~mol} / 1 \mathrm{HClO}_{4}$, followed by mixing by vortex and sonication in ice-cold water for $3 \mathrm{~min}$. Cell lysates were then centrifuged for $3 \mathrm{~min}$ at $3,000 \times g$ and $4^{\circ} \mathrm{C}$, and a fraction $(0.4 \mathrm{ml})$ of the supernatant fraction was mixed with $0.1 \mathrm{ml}$ of $2 \mathrm{~mol} / 1$ HEPES and $0.1 \mathrm{ml}$ of $1 \mathrm{~mol} / 1 \mathrm{Na}_{2} \mathrm{CO}_{3}$. Adenine nucleotide contents were measured by a luminometric method as previously described $[28,29]$.

Effect of metformin on plasma glucose levels and AMPK phosphorylation in liver tissue of wild-type and eNos ${ }^{-1-}$ diabetic mice Mice were made diabetic by intraperitoneal injection of streptozotocin $(120 \mathrm{mg} / \mathrm{kg})$ into male C57/BL6 and $\mathrm{eNos}^{-/-}$mice at 8 weeks of age. At 1 week after injection of streptozotocin, the animals were confirmed to be diabetic by high fed blood glucose levels $(\geq 13.8 \mathrm{mmol} / \mathrm{l})$ and other diabetic features, including polyuria, polydispia and hyperphagia. After fasting for $16 \mathrm{~h}$, the blood glucose levels were measured and mice were immediately injected intraperitoneally with metformin $(250 \mathrm{mg} / \mathrm{kg})$ in $0.9 \%$ 
sterile saline or $0.9 \%$ (wt/vol.) sterile saline only, a similar treatment to that described previously [8, 18]. Blood glucose levels were measured again after $1 \mathrm{~h}$. Diabetic mice received injections of metformin or vehicle as described above for three consecutive days and blood glucose levels were measured again after fasting for $16 \mathrm{~h}$. Immediately after the final measurement of blood glucose levels, the abdomen was cut open and liver tissue of each group was collected and homogenised in lysis buffer. Tissue lysates (50 $\mu \mathrm{g}$ protein/ lane) were used for immunoblotting assay of AMPK phosphorylation using antibodies against AMPK $\alpha$ and phospho-AMPK $\alpha\left(\mathrm{Thr}^{172}\right)$.

Statistical analysis Results are expressed as mean \pm SE per number $(n)$ of animals. Statistical significance was evaluated by ANOVA, unpaired $t$ test (not noted) and paired $t$ test (noted). A value of $p<0.05$ was considered statistically significant.

\section{Results}

Effects of metformin and rotenone on gluconeogenesis and $A M P K \alpha$ phosphorylation in C57/BL6 mice hepatocytes Hepatic gluconeogenesis and AMPK $\alpha$ phosphorylation were measured using freshly isolated hepatocytes. After $2 \mathrm{~h}$ exposure to metformin, hepatic gluconeogenesis was significantly and dose-dependently suppressed at doses between 0.5 and $50 \mathrm{mmol} / 1$ metformin; it was also suppressed by exposure to $100 \mathrm{nmol} / \mathrm{l}$ rotenone (control $115.4 \pm 2.5 \mathrm{nmol} / \mathrm{mg}$ protein, $2 \mathrm{mmol} / 1$ metformin $92.1 \pm$ $3.3 \mathrm{nmol} / \mathrm{mg}$ protein, $p<0.05 \mathrm{vs}$ control; $100 \mathrm{nmol} / 1$ rotenone $91.5 \pm 8.7 \mathrm{nmol} / \mathrm{mg}$ protein, $p<0.05$ vs control; Fig. 1a). Gluconeogenesis at $2 \mathrm{mmol} / \mathrm{l}$ metformin and $100 \mathrm{nmol} / \mathrm{l}$ rotenone were similar ( $p=\mathrm{NS}$ metformin vs rotenone). After $2 \mathrm{~h}$ exposure, metformin $(0.5-50 \mathrm{mmol} / \mathrm{l})$ and $100 \mathrm{nmol} / \mathrm{l}$ rotenone each stimulated phosphorylation of $\mathrm{Thr}^{172}$ of AMPK $\alpha$ (Fig. 1b, c). Increments of phosphorylation relative to control in hepatocytes exposed to $2 \mathrm{mmol} / \mathrm{l}$ metformin and $100 \mathrm{nmol} / 1$ rotenone were almost equivalent (fold increase relative to control $1.79 \pm 0.11$ [metformin] and $1.85 \pm 0.12$ [rotenone], $p=\mathrm{NS}$, metformin vs rotenone). Similar results were observed using primary cultured hepatocytes (Fig. 1d, e). In the time course study of exposure to $2 \mathrm{mmol} / 1 \mathrm{metformin}$, the suppressing effects on gluconeogenesis appeared after $120 \mathrm{~min}(p<0.05$ vs corresponding control; Fig. 1f). In addition, after $60 \mathrm{~min}$ exposure to $2 \mathrm{mmol} / \mathrm{l}$ metformin stimulated phosphorylation of $\mathrm{Thr}^{172}$ of $\mathrm{AMPK} \alpha(p<0.05$ vs pre-exposure; Fig. 1g, h). a

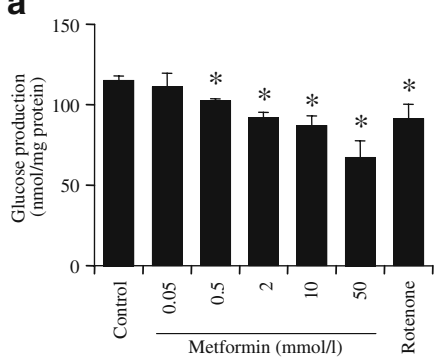

b

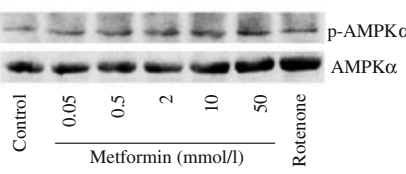

c

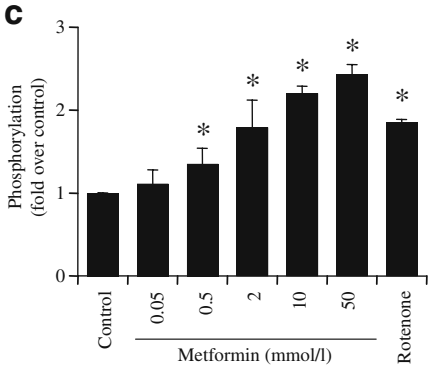

d

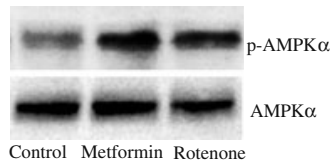

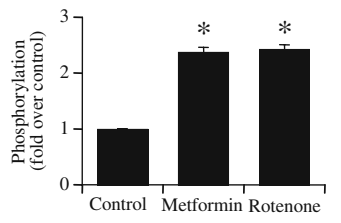

$f$

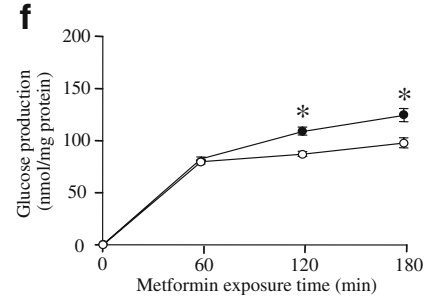

g

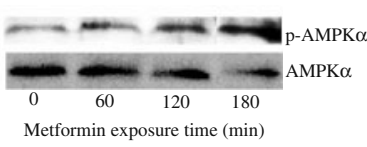

h

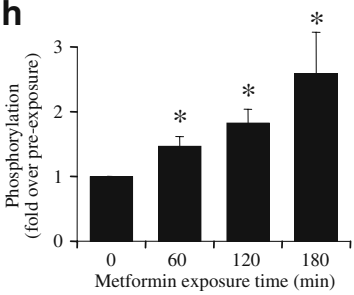

Fig. 1 Metformin and rotenone suppress gluconeogenesis and stimulate $\mathrm{AMPK} \alpha$ phosphorylation in hepatocytes isolated from C57/BL6 mice. a Gluconeogenesis after $2 \mathrm{~h}$ exposure to metformin and rotenone. Metformin (dose-dependently between 0.5 and $50 \mathrm{mmol} / \mathrm{l})$ and rotenone $(100 \mathrm{nmol} / \mathrm{l})$ significantly suppressed gluconeogenesis. b, $\mathbf{c}$ Effects of metformin and rotenone on activation of AMPK. After $2 \mathrm{~h}$ exposure, AMPK $\alpha$ phosphorylation in freshly isolated hepatocytes was significantly stimulated by metformin (dosedependently as above [a]) and rotenone (100 nmol/l). Data are expressed as fold stimulation over control. d, e Effects of metformin and rotenone on activation of AMPK in primary cultured hepatocytes.

After $2 \mathrm{~h}$ exposure, AMPK $\alpha$ phosphorylation was significantly stimulated by metformin $(2 \mathrm{mmol} / \mathrm{l})$ and rotenone $(100 \mathrm{nmol} / \mathrm{l})$. Data are expressed as fold stimulation over control. f Time course of gluconeogenesis with exposure to metformin. Suppressing effects on gluconeogenesis by $2 \mathrm{mmol} / \mathrm{l}$ metformin (white circles) compared with control (black circles) were detected after $120 \mathrm{~min}$. g, h Time course of AMPK activation upon exposure to metformin $(2 \mathrm{mmol} / \mathrm{l})$, which after 60 min stimulated phosphorylation of AMPK $\alpha$ in freshly isolated hepatocytes. Data are expressed as fold stimulation over preexposure. Values (all bar graphs) are means $\pm \mathrm{SE}(n=6), * p<0.05$ vs control (a-f) and pre-exposure (h) 
ATP content and AMP/ATP ratio in C57/BL6 mice hepatocytes In wild-type mice, exposure of freshly isolated hepatocytes to $100 \mathrm{nmol} / 1$ rotenone for $2 \mathrm{~h}$ decreased ATP content and increased the AMP/ATP ratio compared with control (Table 1). However, $2 \mathrm{~h}$ exposure to $2 \mathrm{mmol} / \mathrm{l}$ metformin did not alter ATP content or AMP/ATP ratio compared with control. ATP content and the AMP/ATP ratio at $2 \mathrm{mmol} / \mathrm{l}$ metformin and $100 \mathrm{nmol} / \mathrm{l}$ rotenone were significantly different ( $p<0.01$ metformin vs rotenone).

RNS production by metformin In freshly isolated hepatocytes, exposure to $2 \mathrm{mmol} / \mathrm{l}$ metformin for $1 \mathrm{~h}$ increased DCDHF fluorescence, revealing an increase of $\mathrm{ONOO}^{-}$ generation, whereas $300 \mu \mathrm{mol} / \mathrm{l}$ hydrogen peroxide or $100 \mathrm{nmol} / 1$ rotenone had no effect on DCDHF fluorescence (Table 2). Co-administration of RNS scavengers (vitamin E plus vitamin C) completely suppressed RNS production by metformin.

Immunocytochemical staining of primary cultured hepatocytes with anti-nitrotyrosine antibody was performed to detect $\mathrm{ONOO}^{-}$(Fig. 2). $\mathrm{ONOO}^{-}(10 \mu \mathrm{mol} / \mathrm{l})$ incubated for $5 \mathrm{~min}$ in primary hepatocytes increased nitrotyrosine staining. Exposure to $2 \mathrm{mmol} / \mathrm{l}$ metformin, but not to $100 \mathrm{nmol} / 1$ rotenone for $2 \mathrm{~h}$ increased nitrotyrosine staining (Fig. 2a). Similarly to the DCDHF fluorescence study, coadministration of RNS scavengers (vitamin E plus vitamin C) suppressed nitrotyrosine staining by metformin. Coadministration of L-NAME, a NOS inhibitor, suppressed $\mathrm{ONOO}^{-}$generation by metformin (Fig. 2b).

Effect of direct exposure to $\mathrm{ONOO}^{-}$on $A M P K \alpha$ phosphorylation and $A M P / A T P$ ratio The direct effect of exogenous $\mathrm{ONOO}^{-}$on AMPK phosphorylation in the absence of metformin was examined. Exposure to $\mathrm{ONOO}^{-}$ for $5 \mathrm{~min}$ stimulated phosphorylation of AMPK $\alpha$ by 1 to $100 \mu \mathrm{mol} / 1$ ( $p<0.05$ vs control) (Fig. 3a, b). Exposure to

Table 1 Effect of metformin or rotenone on ATP content and AMP/ ATP ratio in hepatocytes

\begin{tabular}{lll}
\hline $\begin{array}{l}\text { Treatments per } \\
\text { mouse type }\end{array}$ & $\begin{array}{l}\text { ATP } \\
(\mathrm{nmol} / \mathrm{mg} \text { protein })\end{array}$ & AMP/ATP ratio \\
\hline $\begin{array}{l}\text { Wild-type mice } \\
\text { Control }\end{array}$ & $0.45 \pm 0.08$ & $0.98 \pm 0.07$ \\
Metformin & $0.47 \pm 0.05$ & $0.96 \pm 0.12$ \\
Rotenone & $0.13 \pm 0.02^{* *}$ & $1.94 \pm 0.13^{* *}$ \\
eNos $^{-/}$mice & & \\
Control & $0.42 \pm 0.07$ & $1.22 \pm 0.11$ \\
Metformin & $0.41 \pm 0.06$ & $1.27 \pm 0.16$ \\
Rotenone & $0.11 \pm 0.03^{* *}$ & $2.34 \pm 0.23 * *$ \\
\hline
\end{tabular}

Values are means $\pm \mathrm{SE}(n=5)$

${ }^{* *} p<0.01$ vs control
$10 \mu \mathrm{mol} / \mathrm{l} \mathrm{ONOO}^{-}$for $5 \mathrm{~min}$ did not affect ATP content (pre-exposure $0.49 \pm 0.05 \mathrm{nmol} / \mathrm{mg}$ protein; $5 \mathrm{~min} \mathrm{ONOO}^{-}$ $0.50 \pm 0.05 \mathrm{nmol} / \mathrm{mg}$ protein, $p=$ NS vs pre-exposure, $n=5$ ) or the AMP/ATP ratio (pre-exposure $0.99 \pm 0.06,5 \mathrm{~min}$ $\mathrm{ONOO}^{-} 0.98 \pm 0.05, p=\mathrm{NS}$ vs pre-exposure, $n=5$ ).

No effect of metformin on gluconeogenesis, AMPK $\alpha$ phosphorylation or $\mathrm{ONOO}^{-}$generation in hepatocytes lacking eNOS In freshly isolated hepatocytes from $\mathrm{eNos}^{-1-}$ mice, $2 \mathrm{~h}$ exposure to $2 \mathrm{mmol} / \mathrm{l}$ metformin did not suppress gluconeogenesis, whereas exposure to $100 \mathrm{nmol} / 1$ rotenone suppressed gluconeogenesis to a similar degree to that observed in wild-type hepatocytes (control 110.1 $4.4 \mathrm{nmol} / \mathrm{mg}$ protein, metformin $107.0 \pm 3.9 \mathrm{nmol} / \mathrm{mg}$ protein, $p=\mathrm{NS}$ vs control; rotenone $81.6 \pm 8.8 \mathrm{nmol} / \mathrm{mg}$ protein, $p<0.05$ vs control; Fig. 4a). Metformin did not stimulate AMPK $\alpha$ phosphorylation in freshly isolated hepatocytes from $\mathrm{eNos}^{-/-}$mice, whereas rotenone significantly stimulated AMPK $\alpha$ phosphorylation (fold increase relative to control at $2 \mathrm{~h}$ : metformin $0.96 \pm 0.12, p=\mathrm{NS}$ vs control; rotenone $1.94 \pm 0.13, p<0.05$ vs control; Fig. $4 \mathrm{~b}, \mathrm{c}$ ). Similarly, in primary cultured hepatocytes, metformin also did not stimulate, whereas rotenone significantly stimulated AMPK $\alpha$ phosphorylation (Fig. 4d, e). Metformin also did not increase nitrotyrosine staining in primary cultured hepatocytes from $\mathrm{eNos}^{-/-}$mice, indicating no generation of $\mathrm{ONOO}^{-}$(Fig. 4f). In addition, nitrotyrosine staining was not induced by $2 \mathrm{~h}$ exposure to rotenone. Exposure of $\mathrm{eNos}^{-/-}$freshly isolated hepatocytes to $100 \mathrm{nmol} / 1$ rotenone also decreased ATP content and increased the AMP/ATP ratio, whereas exposure to metformin had not effect (Table 1). Recently, it was reported that metformin is first transported across the plasma membrane before exerting its cellular action, a step mediated by OCT1 [30]. To exclude involvement of OCT1 in $\mathrm{eNos}^{-/-}$mice, we confirmed that levels of OCT1 protein in freshly isolated hepatocytes from $\mathrm{eNos}^{-1-}$ mice were similar to those in wild-type mice hepatocytes (Fig. 4g).

Essential role of eNOS in lowering of glucose levels by metformin in diabetic mice in vivo To determine whether metformin lowers fasting blood glucose levels in the absence of eNOS, metformin $(250 \mathrm{mg} / \mathrm{kg})$ was injected intraperitoneally into streptozotocin-induced diabetic wildtype or $\mathrm{eNos}^{-/-}$mice. Characteristics of wild-type and $e \mathrm{Nos}^{-/-}$mice used in the experiments showed no significant differences in body weight, fasting blood glucose levels or fed blood glucose levels before streptozotocin injection at 8 weeks of age among the four groups (Table 3).

Fasting blood glucose levels were lowered by about $3.9 \mathrm{mmol} / \mathrm{l}$ at $1 \mathrm{~h}$ after single administration of metformin in overnight-fasted wild-type diabetic mice, whereas those in overnight-fasted $\mathrm{eNos}^{-/-}$diabetic mice were not altered 
Table 2 Effect of metformin on RNS production

\begin{tabular}{|c|c|c|}
\hline Treatments & No addition & $\begin{array}{l}\text { Addition of } \\
\text { vitamins } E \text { and } C\end{array}$ \\
\hline Control & $1.03 \pm 0.01$ & $0.94 \pm 0.01 * *$ \\
\hline Metformin $(2 \mathrm{mmol} / \mathrm{l})$ & $1.15 \pm 0.04^{*}$ & $0.95 \pm 0.01 * *$ \\
\hline Rotenone $(100 \mathrm{nmol} / \mathrm{l})$ & $1.03 \pm 0.02$ & $0.99 \pm 0.01 * *$ \\
\hline Hydrogen peroxide $(300 \mu \mathrm{mol} / \mathrm{l})$ & $1.02 \pm 0.02$ & $0.98 \pm 0.01 * *$ \\
\hline $\mathrm{ONOO}^{-}(10 \mu \mathrm{mol} / \mathrm{l})$ & $1.21 \pm 0.05^{*}$ & $1.00 \pm 0.01 * *$ \\
\hline
\end{tabular}

Data are expressed as the value at 60 min divided by the value at time zero (fold increase); values are means $\pm \mathrm{SE}(n=8)$

${ }^{*} p<0.05$ vs control; ${ }^{* *} p<0.01$ vs corresponding values without RNS scavengers

(Table 3). Administration of vehicle (saline) alone in overnight-fasted wild-type diabetic mice did not alter fasting blood glucose levels after single administration, as was also found in overnight-fasted $\mathrm{eNos}^{-/}$diabetic mice (Table 3). Following the first injection, daily administration of metformin was continued for two more days. Administration of metformin for three consecutive days lowered fasting blood glucose levels by about $7.1 \mathrm{mmol} / 1$ in wildtype diabetic mice, whereas it had no lowering effect on fasting blood glucose in diabetic $\mathrm{eNos}^{-1-}$ mice (Table 3). Administration of vehicle (saline) alone in overnight-fasted wild-type mice did not alter fasting blood glucose levels

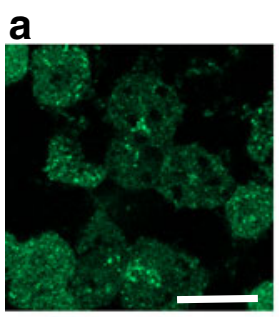

Control

b

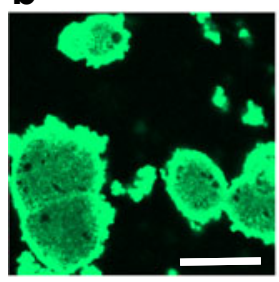

$\mathrm{ONOO}^{-}$

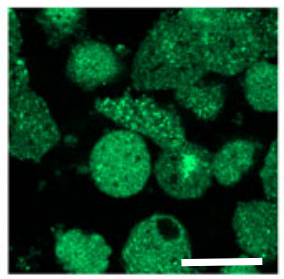

Metformin

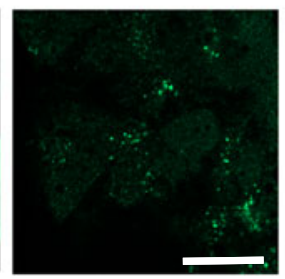

Metformin +vitamins $\mathrm{C}$ and $\mathrm{E}$

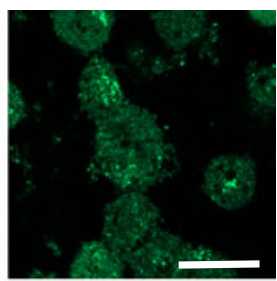

Rotenone

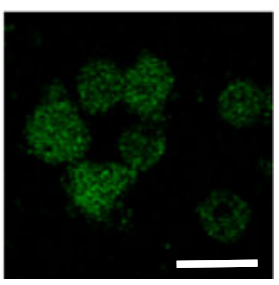

Metformin + L-NAME
Fig. 2 Immunocytochemical staining with anti-nitrotyrosine antibody for detection of $\mathrm{ONOO}^{-}$generation. $\mathrm{ONOO}^{-}(10 \mu \mathrm{mol} / \mathrm{l})$ incubated for $5 \mathrm{~min}$ was used as a positive control. a Exposure to metformin ( $2 \mathrm{mmol} / \mathrm{l}$ ) for $2 \mathrm{~h}$ increased staining, but exposure to rotenone $(100 \mathrm{nmol} / \mathrm{l})$ for the same time did not. b $\mathrm{ONOO}^{-}$generation induced by metformin was decreased by co-administration with RNS scavengers ( $5 \mathrm{mmol} / 1 \quad \alpha$-tocopherol [vitamin E] plus $2.3 \mathrm{mmol} / 1$ ascorbate [vitamin C] ) and a NOS inhibitor (1 mmol/1 L-NAME), respectively. Confocal microscopy, magnifications $\times 100$; scale bars $50 \mu \mathrm{m}$ a

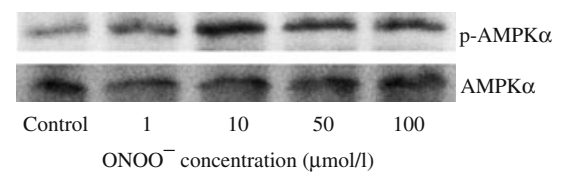

b

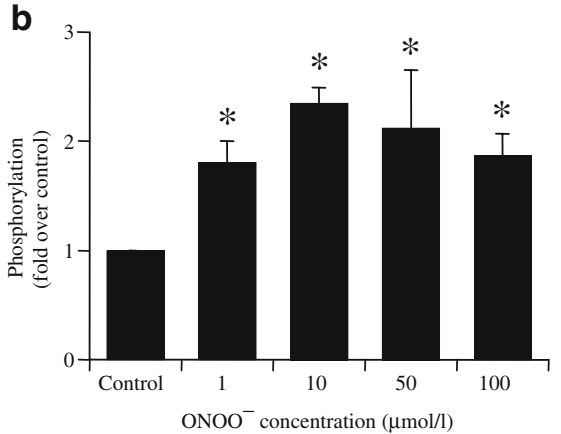

Fig. 3 Exogenous $\mathrm{ONOO}^{-}$stimulates $\mathrm{AMPK} \alpha$ phosphorylation in freshly isolated hepatocytes. a Blot showing that direct exposure to $\mathrm{ONOO}^{-}$for $5 \mathrm{~min}$ at doses ranging from 1 to $100 \mu \mathrm{mol} / 1$ stimulated AMPK $\alpha$ phosphorylation. b Quantification with data expressed as fold stimulation over control. Values are means \pm SE $(n=4),{ }^{*} p<0.05$ vs control

after administration for three consecutive days, as was also the case in $\mathrm{eNos}^{-/-}$mice (Table 3).

Lack of effects of metformin in vivo on AMPKQ phosphorylation in liver tissues lacking eNOS In liver tissue samples collected after three consecutive days of administration, metformin stimulated phosphorylation of AMPK $\alpha$ in wild-type mice (metformin $2.17 \pm 0.30$ [fold increase relative to vehicle], $p<0.05$ vs vehicle; Fig. $5 \mathrm{a}$, b). However, stimulation of AMPK $\alpha$ phosphorylation by metformin was not observed in liver tissues of $\mathrm{eNos}^{-/-}$mice (metformin $0.97 \pm 0.12$ [fold increase relative to vehicle], $p=\mathrm{NS}$ vs saline; Fig. 5a, c).

\section{Discussion}

In the present study, we show for the first time that activation of AMPK and the inhibitory effect on hepatic gluconeogenesis by metformin are mediated by generation of the RNS, $\mathrm{ONOO}^{-}$. We also showed that eNOS plays an important role in metformin action in liver.

We investigated the metformin-RNS-AMPK pathway for its suppressing effects on hepatic gluconeogenesis. Because recent studies have shown that metformin activates AMPK through the RNS, $\mathrm{ONOO}^{-}$, in BAEC [18], we evaluated RNS production in liver, the major target of metformin action. We found that metformin increased $\mathrm{ONOO}^{-}$generation and that $\mathrm{ONOO}^{-}$itself activates AMPK, which is induced in only $5 \mathrm{~min}$. A previous study found that AMPK phosphorylation by metformin does not appear within $10 \mathrm{~min}$ but only after $30 \mathrm{~min}$ [31]. Consistent 
a

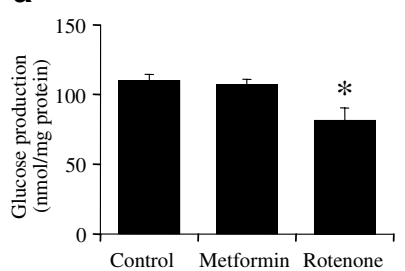

e

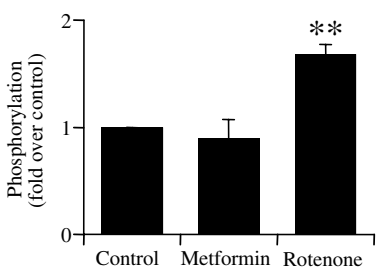

b

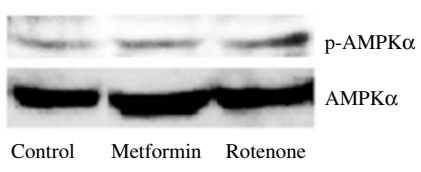

f

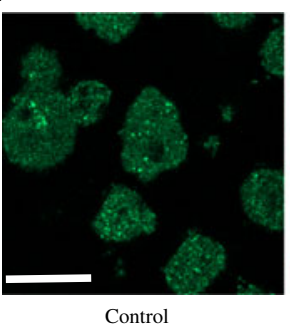

C

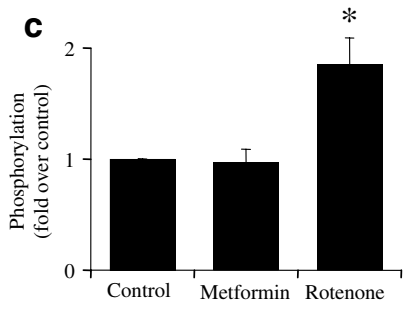

d

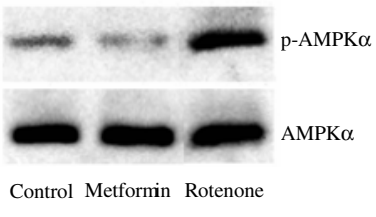

g

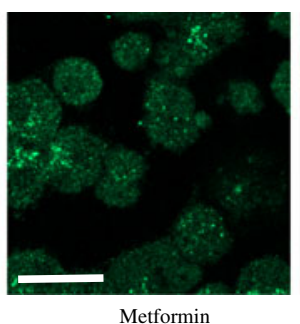

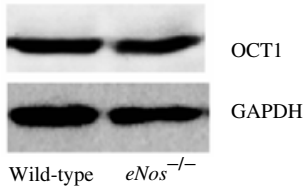

Fig. 4 Lack of effects of metformin on suppression of gluconeogenesis, AMPK $\alpha$ phosphorylation and $\mathrm{ONOO}^{-}$generation in hepatocytes lacking eNOS. a Metformin $(2 \mathrm{mmol} / \mathrm{l})$ did not suppress gluconeogenesis after $2 \mathrm{~h}$ exposure in hepatocytes lacking eNOS, but rotenone $(100 \mathrm{nmol} / \mathrm{l})$ suppressed gluconeogenesis to a similar degree to that observed in wild-type hepatocytes. Values are means $\pm \operatorname{SE}(n=6),{ }^{*} p<$ 0.05 vs control. b Blot showing that AMPK $\alpha$ phosphorylation was not stimulated by metformin $(2 \mathrm{mmol} / \mathrm{l})$, but was stimulated by rotenone $(100 \mathrm{nmol} / \mathrm{l})$ after $2 \mathrm{~h}$ exposure in freshly isolated hepatocytes; (c) quantification with data expressed as fold stimulation over control. Values are means $\pm \operatorname{SE}(n=4),{ }^{*} p<0.05$ vs control. d Blot showing that AMPK $\alpha$ phosphorylation was not stimulated by metformin $(2 \mathrm{mmol} / \mathrm{l})$,

with that study, our data showed that AMPK phosphorylation by metformin did not appear within $15 \mathrm{~min}$, but only after more than $30 \mathrm{~min}$ (data not shown). Thus, $\mathrm{ONOO}^{-}$ generation appears to precede AMPK phosphorylation after exposure to metformin. $\mathrm{ONOO}^{-}$is generated by nitric oxide and superoxide anions; intra-hepatocellular nitric oxide is produced by NOS. In the present study, the NOS inhibitor, L-NAME, suppressed $\mathrm{ONOO}^{-}$production by metformin. but was stimulated by rotenone $(100 \mathrm{nmol} / \mathrm{l})$ after $2 \mathrm{~h}$ exposure in primary cultured hepatocytes, with (e) bar graph showing data expressed as fold stimulation over control. Values are means $\pm \mathrm{SE}$ $(n=5),{ }^{* *} p<0.01$ vs control. f Immunocytochemical staining (confocal microscopy) with anti-nitrotyrosine antibody in hepatocytes lacking eNOS. Exposure to metformin $(2 \mathrm{mmol} / \mathrm{l})$ and rotenone $(100 \mathrm{nmol} / \mathrm{l})$ for $2 \mathrm{~h}$ did not increase staining. Magnification $\times 100$, scale bar $50 \mu \mathrm{m}$. g Levels of OCT1 protein in wild-type and $\mathrm{eNos}^{-/-}$mice hepatocytes. OCT1 levels in $\mathrm{eNos}^{-/-}$mice hepatocytes were similar to those in wildtype mice hepatocytes. Findings normalised to glyceraldehyde-3phosphate dehydrogenase (GAPDH)

This suggests that nitric oxide production by hepatocellular NOS is required for $\mathrm{ONOO}^{-}$production by metformin. Since eNOS is the representative subtype of the NOS family for generation of $\mathrm{ONOO}^{-}$in liver [17], we sought to determine whether eNOS is required for $\mathrm{ONOO}^{-}$production by metformin. Using eNOS-deficient mice, we were able to demonstrate that eNOS is essential for metformin action in liver. Thus metformin increases $\mathrm{ONOO}^{-}$produc-

Table 3 Effect of metformin on blood glucose levels in wild-type and $\mathrm{eNos}^{-/-}$diabetic mice

\begin{tabular}{|c|c|c|c|c|c|c|}
\hline \multirow[t]{2}{*}{ Treatments per mouse type } & \multicolumn{3}{|c|}{ Pre streptozotocin } & \multicolumn{3}{|c|}{ Post streptozotocin } \\
\hline & $\begin{array}{l}\text { Body weight } \\
\text { (g) }\end{array}$ & $\begin{array}{l}\text { FBG } \\
(\mathrm{mmol} / \mathrm{l})\end{array}$ & $\begin{array}{l}\text { Fed BG } \\
(\mathrm{mmol} / \mathrm{l})\end{array}$ & $\begin{array}{l}\text { FBG } \\
(\mathrm{mmol} / \mathrm{l})\end{array}$ & $\begin{array}{l}\text { BG }(\mathrm{mmol} / \mathrm{l}) \\
\text { at } 1 \mathrm{~h} \mathrm{PM}\end{array}$ & $\begin{array}{l}\text { FBG }(\mathrm{mmol} / \mathrm{l}) \text { after } \\
3 \text { days met }\end{array}$ \\
\hline \multicolumn{7}{|l|}{ Wild-type mice } \\
\hline Saline & $20.3 \pm 0.4$ & $3.7 \pm 0.2$ & $8.2 \pm 0.5$ & $16.0 \pm 2.7$ & $17.2 \pm 3.1$ & $16.6 \pm 3.3$ \\
\hline Metformin & $20.4 \pm 0.3$ & $3.7 \pm 0.2$ & $8.0 \pm 0.3$ & $16.6 \pm 2.8$ & $12.7 \pm 3.0 * *$ & $9.5 \pm 1.9 * *$ \\
\hline \multicolumn{7}{|l|}{$\mathrm{eNos}^{-1-}$ mice } \\
\hline Saline & $20.5 \pm 0.3$ & $3.6 \pm 0.2$ & $7.9 \pm 0.4$ & $15.0 \pm 1.9$ & $17.3 \pm 2.4$ & $16.9 \pm 2.7$ \\
\hline Metformin & $20.7 \pm 0.3$ & $3.5 \pm 0.2$ & $8.1 \pm 0.5$ & $15.8 \pm 1.6$ & $19.0 \pm 1.9$ & $16.5 \pm 2.1$ \\
\hline
\end{tabular}

Values are means $\pm \operatorname{SE}(n=8)$

${ }^{* *} p<0.01$ vs the value of pre-injection intraperitoneally with metformin in saline or saline only, paired $t$ test

BG, blood glucose; FBG, fasting blood glucose; met, metformin; PM, post-metformin 


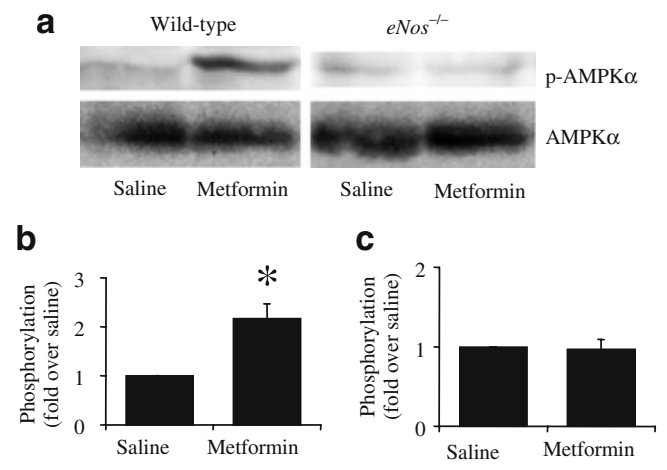

Fig. 5 Lack of effects of metformin in vivo on AMPK $\alpha$ phosphorylation in liver tissues deficient in eNOS. a Blot showing that metformin stimulated phosphorylation of AMPK $\alpha$ in liver tissues of wild-type diabetic mice after administration for three consecutive days. b Quantification of blot for wild-type and (c) $\mathrm{eNos}^{-1-}$ mice. Metformin did not stimulate $(\mathbf{a}, \mathbf{c})$ phosphorylation of AMPK $\alpha$ in liver tissues of $\mathrm{eNos}^{-1-}$ diabetic mice after metformin administration for three consecutive days. Data $(\mathbf{b}, \mathbf{c})$ are expressed as fold stimulation over saline. Values are means $\pm \operatorname{SE}(n=5), * p<0.05$ vs vehicle

tion, which is followed by AMPK activation and suppression of gluconeogenesis.

Although metformin has been reported not to affect the ATP content of hepatocytes [32], several studies have found that metformin decreased ATP content and/or increased the AMP/ATP ratio in hepatocytes [23, 33], possibly a result of metformin's suppressive effect on complex I activity in the respiratory chain [34] and one that plays an important role in AMPK activation by metformin. While metformin was found not to affect ATP content and the AMP/ATP ratio in the present study, the AMP/ATP ratio might nevertheless play an important role in AMPK activation by metformin because AMPK is sensitive to changes in the AMP/ATP ratio at levels too slight to be detected by measurement of the total adenine nucleotide content of whole cells [35]. Interestingly, metformin activates AMPK with a smaller increase in the AMP/ATP ratio than that effected by mitochondrial uncoupler and rosiglitazone [16] and without affecting the ADP/ATP ratio [10]. These results suggest that, apart from increases in the AMP/ATP ratio, other important mechanisms may be involved in AMP activation by metformin.

Rotenone inhibits complex I of the mitochondrial respiratory chain and decreases oxidative phosphorylation, leading to ATP depletion and an increase in the AMP/ATP ratio, which results in stimulation of AMPK phosphorylation. In the present study we observed that while $2 \mathrm{mmol} / \mathrm{l}$ metformin and $100 \mathrm{nmol} / \mathrm{l}$ rotenone had similar effects on gluconeogenesis and AMPK phosphorylation, the AMP/ ATP ratio increased prominently only upon exposure to rotenone but not upon exposure to metformin. These results indicate that complex I inhibition alone is unlikely to explain the action of metformin. Interestingly, metformin significantly increased RNS in contrast to the lack of effect of rotenone on RNS. Furthermore, a decrease in metformininduced RNS production by eNOS disruption abolished activation of AMPK by metformin. These results demonstrate that RNS is a regulator distinct from the AMP/ATP ratio in AMPK activation by metformin.

Some groups have reported that eNOS acts upstream of AMPK activation in BAEC [18], while other groups have reported that eNOS acts downstream of AMPK activation in capillary endothelial cells and in cardiomyocytes [21]. In the present study, we show that, in wild-type hepatocytes, direct exposure to $\mathrm{ONOO}^{-}$activates AMPK and that rotenone activates AMPK without increase in $\mathrm{ONOO}^{-}$production, supporting the former notion [18] in hepatocytes.

It is well known that high levels of RNS have deleterious effects on cell function and viability [17]. On the other hand, the low levels of RNS seen in physiological conditions are required for maintaining normal cell functions such as signal transduction [36]. For example, it has been reported that RNS production induced by skeletal muscle contraction is correlated with glucose uptake [20]. Thus, RNS has protective and damaging effects on cells. Indeed, the RNS produced by metformin at a dose used in the present study $(2 \mathrm{mmol} / \mathrm{l})$ should have beneficial effects on hepatic glucose metabolism through AMPK activation.

We demonstrate in the present study that AMPK activation by metformin in hepatocytes is dependent on RNS. We also demonstrate that eNOS plays an important role in suppressing hepatic gluconeogenesis in vitro as well as in lowering fasting blood glucose levels in vivo. It is generally accepted that fasting blood glucose levels are determined by hepatic gluconeogenesis, which suggests that eNOS is required for metformin's action on fasting blood glucose levels.

In the present study, we have elucidated a novel mechanism for metformin action. However, some limitations of this study must be considered. In our in vivo metformin experiments, the mice were injected intraperitoneally with $250 \mathrm{mg} / \mathrm{kg}$ metformin in $0.9 \%$ sterile saline, which is a similar dosage to that used previously $[8,18]$. This protocol using a high dose of metformin for rodents may cause a very distinct acute response. Therefore, we cannot exclude the possibility that the acute hepatocellular response to AMPK activation by metformin in the present study differs from the clinical effects of metformin when used to treat patients with type 2 diabetes. To elucidate the detailed mechanisms of AMPK activation by metformin in liver, which may provide novel therapeutic targets for type 2 diabetes, further investigations are required. 
Acknowledgements This study was supported by Scientific Research Grants, a Grant for Leading Project for Biosimulation from the Ministry of Education, Culture, Sports, Science and Technology of Japan, and by a grant from CREST of Japan Science and Technology Cooperation. Support was also provided in the form of a grant from the Ministry of Health, Labor and Welfare, Japan, and also by Kyoto University Global COE Program 'Center for Frontier Medicine'.

Duality of interest The authors declare that there is no duality of interest associated with this manuscript.

\section{References}

1. Nathan DM, Buse JB, Davidson MB et al (2008) Management of hyperglycaemia in type 2 diabetes mellitus: a consensus algorithm for the initiation and adjustment of therapy. Update regarding the thiazolidinediones. Diabetologia 51:8-11

2. Nathan DM, Buse JB, Davidson MB et al (2006) Management of hyperglycaemia in type 2 diabetes: a consensus algorithm for the initiation and adjustment of therapy. A consensus statement from the American Diabetes Association and the European Association for the Study of Diabetes. Diabetologia 49:1711-1721

3. Inzucchi SE, Maggs DG, Spollett GR et al (1998) Efficacy and metabolic effects of metformin and troglitazone in type II diabetes mellitus. N Engl J Med 338:867-873

4. Scarpello JH, Howlett HC (2008) Metformin therapy and clinical uses. Diab Vasc Dis Res 5:157-167

5. Bailey CJ (1992) Biguanides and NIDDM. Diabetes Care 15:755772

6. UK Prospective Diabetes Study (UKPDS) Group (1998) Effect of intensive blood-glucose control with metformin on complications in overweight patients with type 2 diabetes (UKPDS 34). Lancet 352:854-865

7. Brunmair B, Staniek K, Gras F et al (2004) Thiazolidinediones, like metformin, inhibit respiratory complex I. Diabetes 53:1052-1059

8. Shaw RJ, Lamia KA, Vasquez D et al (2005) The kinase LKB1 mediates glucose homeostasis in liver and therapeutic effects of metformin. Science 310:1642-1646

9. Zhou G, Myers R, Li Y, Chen Y et al (2001) Role of AMPactivated protein kinase in mechanism of metformin action. J Clin Invest 108:1167-1174

10. Hawley SA, Gadalla AE, Olsen GS, Hardie DG (2002) The antidiabetic drug metformin activates the AMP-activated protein kinase cascade via an adenine nucleotide-independent mechanism. Diabetes 51:2420-2425

11. Tian R, Musi N, D'Agostino J, Hirshman MF, Goodyear LJ (2001) Increased adenosine monophosphate-activated protein kinase activity in rat hearts with pressure-overload hypertrophy. Circulation 104:1664-1669

12. Hardie DG (2004) The AMP-activated protein kinase pathwaynew players upstream and downstream. J Cell Sci 117:5479-5487

13. Hardie DG, Hawley SA, Scott JW (2006) AMP-activated protein kinase - development of the energy sensor concept. J Physiol 574: $7-15$

14. El-Mir MY, Nogueira V, Fontaine E, Ave'ret N, Rigoulet M, Leverve X (2000) Dimethylbiguanide inhibits cell respiration via an indirect effect targeted on the respiratory chain complex I. J Biol Chem 275:223-228

15. Owen MR, Doran E, Halestrap AP (2000) Evidence that metformin exerts its anti-diabetic effects through inhibition of complex 1 of the mitochondrial respiratory chain. Biochem J 348:607-614
16. Fryer LG, Parbu-Patel A, Carling D (2002) The anti-diabetic drugs rosiglitazone and metformin stimulate AMP-activated protein kinase through distinct signaling pathways. J Biol Chem 277:25226-25232

17. Pacher P, Beckman JS, Liaudet L (2007) Nitric oxide and $\mathrm{ONOO}^{-}$ in health and disease. Physiol Rev 87:315-424

18. Zou MH, Kirkpatrick SS, Davis BJ et al (2004) Activation of the AMP-activated protein kinase by the anti-diabetic drug metformin in vivo. Role of mitochondrial reactive nitrogen species. J Biol Chem 279:43940-43951

19. Davis BJ, Xie Z, Viollet B, Zou MH (2006) Activation of the AMP-activated kinase by antidiabetes drug metformin stimulates nitric oxide synthesis in vivo by promoting the association of heat shock protein 90 and endothelial nitric oxide synthase. Diabetes 55:496-505

20. Ross RM, Wadley GD, Clark MG, Rattigan S, McConell GK (2007) Local nitric oxide synthase inhibition reduces skeletal muscle glucose uptake but not capillary blood flow during in situ muscle contraction in rats. Diabetes 56:2885-2892

21. Chen ZP, Mitchelhill KI, Michell BJ et al (1999) AMP-activated protein kinase phosphorylation of endothelial NO synthase. FEBS Lett 443:285-289

22. Fujiwara H, Hosokawa M, Zhou X et al (2008) Curcumin inhibits glucose production in isolated mice hepatocytes. Diabetes Res Clin Pract 80:185-191

23. Argaud D, Roth H, Wiernsperger N, Leverve XM (1993) Metformin decreases gluconeogenesis by enhancing the pyruvate kinase flux in isolated rat hepatocytes. Eur J Biochem 213:13411348

24. Kooy NW, Royall JA, Ischiropoulos H (1997) Oxidation of $2^{\prime}, 7^{\prime}$-dichlorofluorescin by $\mathrm{ONOO}^{-}$. Free Radic Res 27:245254

25. Crow JP (1997) Dichlorodihydrofluorescein and dihydrorhodamine 123 are sensitive indicators of $\mathrm{ONOO}^{-}$in vitro: implications for intracellular measurement of reactive nitrogen and oxygen species. Nitric Oxide 2:145-157

26. Possel H, Noack H, Augustin W, Keilhoff G, Wolf G (1997) 2,7Dihydrodichlorofluorescein diacetate as a fluorescent marker for $\mathrm{ONOO}^{-}$formation. FEBS Lett 416:175-178

27. Kominato R, Fujimoto S, Mukai E et al (2008) Src activation generates reactive oxygen species and impairs metabolism-secretion coupling in diabetic Goto-Kakizaki and ouabain-treated rat pancreatic islets. Diabetologia 51:12261235

28. Nabe K, Fujimoto S, Shimodahira M et al (2006) Diphenylhydantoin suppresses glucose-induced insulin release by decreasing cytoplasmic $\mathrm{H}^{+}$concentration in pancreatic islets. Endocrinology 147:2717-2727

29. Fujimoto S, Mukai E, Hamamoto Y et al (2002) Prior exposure to high glucose augments depolarization-induced insulin release by mitigating the decline of ATP level in rat islets. Endocrinology 143:213-221

30. Shu Y, Sheardown SA, Brown C et al (2007) Effect of genetic variation in the organic cation transporter 1 (OCT1) on metformin action. J Clin Invest 117:1422-1431

31. Xie Z, Dong Y, Scholz R, Neumann D, Zou MH (2008) Phosphorylation of LKB1 at serine 428 by protein kinase $\mathrm{C}-\zeta$ is required for metformin-enhanced activation of the AMPactivated protein kinase in endothelial cells. Circulation 117: 952-962

32. Wollen N, Bailey CJ (1988) Inhibition of hepatic gluconeogenesis by metformin. Synergism with insulin. Biochem Pharmacol $37: 4353-4358$

33. Guigas B, Bertrand L, Taleux N et al (2006) 5-Aminoimidazole4-carboxamide-1-beta-D-ribofuranoside and metformin inhibit 
hepatic glucose phosphorylation by an AMP-activated protein kinase-independent effect on glucokinase translocation. Diabetes 55:865-874

34. Hinke SA, Martens GA, Cai Y et al (2007) Methyl succinate antagonises biguanide-induced AMPK-activation and death of pancreatic beta-cells through restoration of mitochondrial electron transfer. Br J Pharmacol 150:1031-1043
35. Zhang L, He H, Balschi JA (2007) Metformin and phenformin activate AMP-activated protein kinase in the heart by increasing cytosolic AMP concentration. Am J Physiol Heart Circ Physiol 293:H457-H466

36. Bashan N, Kovsan J, Kachko I, Ovadia H, Rudich A (2009) Positive and negative regulation of insulin signaling by reactive oxygen and nitrogen species. Physiol Rev 89:27-71 